\title{
MUCOADHESIVE CHITOSAN MICROSPHERES OF GEFITINIB
}

\author{
Original Article
}

\author{
MOHNISH SONI, ARTI MAJUMDAR, NEELESH MALVIYA
}

Smriti College of Pharmaceutical Education, 4/3, Pipaliya Kumar Kakkar road, MR-11, Mayakhedi, Nipaniya, Indore (M. P.) Email: mohnishsn39@gmail.com

Received: 11 Jun 2018, Revised and Accepted: 07 Aug 2018

\begin{abstract}
Objective: Gefitinib, Epidermal Growth Factor-Tyrosine Kinase Inhibitor (EGFR-TKI); has promisingly shown activity against Non-Small-Scale Lung Cancer. Currently, the formulations of this drug available are in Tablets, Capsules and liposomal suspensions taken by the oral route. These have certain disadvantages in gastrointestinal disorders like irritation of GI mucosal layer, bleeding, non-patient compliance and low bioavailability due to low aqueous solubility and thus low bioavailability. The purpose of this study was to formulate and evaluate Chitosan-based Microparticles of Gefitinib for maintaining the therapeutic index and limits its side effects.
\end{abstract}

Methods: Chitosan microspheres cross-linked with glutaraldehyde were prepared by solvent evaporation technique which is then analyzed for its particle size, encapsulation efficiency, swelling index.

Results: The release rate of the drug can be increased by using chitosan-based carrier system which will enhance its bioavailability. By this work, the anticancer activity of Gefitinib in non-small-scale lung cancer will be successfully determined.

Conclusion: It has been concluded that microspheres can be prepared by solvent evaporation technique by varying the concentration of chitosan and tween-20. Chitosan used in this work is of $85 \%$ degree of deacetylation, $25 \%$ solution of Gluteraldehyde suitable for the formulation of these microspheres. Optimized temperature was selected as $65^{\circ} \mathrm{C}$, and the rotation speed was taken as $1200 \mathrm{rpm}$. Finally, the objectives planned for this research work was performed and evaluated and shown promising results as the dosing frequency is reduced and maximize for $3 \mathrm{~d}$ rather than once in a day as per the current formulation available in the market now with a low dosage regimen of $100 \mathrm{mg}$ of dosage strength, administer by pulmonary route. Microparticulate drug delivery system from microspheres is able to deliver the drug in a sustained release manner for the long period of time successfully.

Keywords: Microparticles, Gefitinib, Epidermal Growth Factor Inhibitor, Tyrosine Kinase, Lung Cancer, Bioavailability

(c) 2018 The Authors. Published by Innovare Academic Sciences Pvt Ltd. This is an open-access article under the CC BY license (http://creativecommons.org/licenses/by/4.0/) DOI: http://dx.doi.org/10.22159/ijcpr.2018v10i5.29686

\section{INTRODUCTION}

Chitosan is a biodegradable, biocompatible and non-toxic natural polymer thus it has a great potential for biomedical and pharmaceutical applications. Chitosan is cationic in nature, so it has good mucoadhesive and membrane permeability enhancing properties. Chitosan has previously been shown to enhance the mucosal absorption of various compounds in a drug delivery system and have adjuvant activity in the mucosal immune response. Chitosan is a renowned rate controlling polymer for drug release which helps in prolongation of the duration of action and delivering the drug to the specific sites in the body. Also, chitosan does not cause any hypersensitivity or allergic reactions with living tissues [1]. It breaks down slowly to amino sugars which is harmless and completely absorbed by the human body. There are so many reports that demonstrated the efficacy of chitosan microspheres as a vehicle for transport of drugs in the body. Thus, this proves to be safe, widely available and cost-effective.

Microparticle, also called as 'microsphere' or 'microcapsule' have many applications in medicine. In most cases, microparticles are used as drug carriers to deliver the drug to the desired site and slowly release the encapsulated drug over a desired period of time to maintain an effective local drug concentration. Microparticles also have novel application in the foods, medical devices, chemical coatings, personal health testing kits, biosensors as per security systems, high throughput screening techniques, and water purification units for manned spacecraft [2]. Thus; Microparticles are that type of drug delivery systems where the particle size ranges from 1 micron (one-thousandth of a $\mathrm{mm}$ ) to few $\mathrm{mm}$. The microencapsulation technology allows protection of drug from the environment, stabilization of sensitive drug substances, elimination of incompatibilities, or masking of unpleasant taste. Hence, they play an important role as drug delivery systems aiming at improved bioavailability of conventional drugs and minimizing side effects.

\section{MATERIALS AND METHODS}

\section{Materials}

Chitosan of medium molecular weight (240 kD) having 85\% degree of deacetylation obtained from Yarrow Chemicals Mumbai, Gefitinib was obtained as a gift sample from Natco Pharma Pvt. Ltd Hyderabad, Acetic acid was purchased from Merck Chemicals, S. K. Traders Indore, Glutaraldehyde (25\% aqueous solution) obtained from Loba Chemicals. All the chemicals, reagents and solvents used were of the highest analytical grades.

\section{Equipment}

Ultra-Sonicator bath-type, Shimadzu Digital Weighing Balance having 2.20 kg capacity, 2 MLH Remi Motors Magnetic Stirrer, Shimadzu-1800 UV Spectrophotometer, FTLA 2000 meter Toledo FTIR, Veego 6 Station Dissolution Apparatus, Horiba Nano Particle Sized Analyzer.

\section{Microspheres preparation}

Chitosan-based microspheres are prepared by the reported method with some modifications. A weighed quantity of Chitosan $(1,1.5,2 \mathrm{gm})$ was dissolved in $5 \%$ acetic acid solution and was stirred under room temperature $\left(25^{\circ} \mathrm{C}\right)$ on a magnetic stirrer at $700 \mathrm{rpm}$. Then the drug Gefitinib was loaded (100 mg) into this chitosan solution and stirred continuously. After obtaining a homogeneous solution, this was sonicated on ultrasonicator for $10 \mathrm{~min}$ to remove air bubbles during stirring. This solution was filled into $10 \mathrm{ml}$ injection contains 24 gauze needle [3]. By adding this solution in injection drop by drop at a rate of 1 $\mathrm{ml} / \mathrm{min}$ into the base solvent system containing $5 \mathrm{ml}$ petroleum ether and $10 \mathrm{ml}$ of heavy liquid paraffin containing tween 20 as an emulsifier. Then, these microspheres are obtained by solvent evaporation technique by using REMI Motors 2 MLH Magnetic Stirrer. After half an hour of continuous stirring at $60{ }^{\circ} \mathrm{C}$, add $25 \%$ glutaraldehyde solution and stirred this solution continuously. This was subjected to filtration, washing three times with $\mathrm{N}$-hexane and then air dried. For the solvent evaporation process, the process conditions were: concentration of 
chitosan, the concentration of emulsifier (Tween 20) and temperature. Gefitinib loaded chitosan microspheres were prepared by this technique.

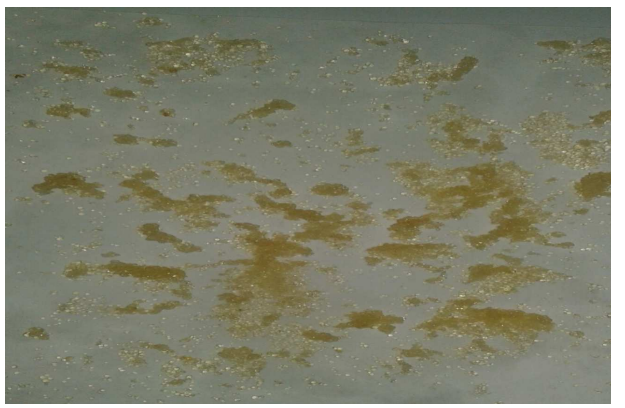

Fig. 1: Photograph of gefitinib chitosan microspheres

\section{Optimization}

Optimization of the Gefitinib-Chitosan Microspheres by Solvent Evaporation Method was based on following parameters given by $3^{2}$ factorial design [4]

In $3^{2}$ factorial design

3 = Levels like Low (-1), Medium (0), High (+1) and

2 = Factors like independent variations and responses.

- The independent variations in this design are: $\mathrm{X}_{1}=$ Concentration of chitosan, and

$\mathrm{X}_{2}=$ Concentration of Tween-20

- The responses in this design are: $\mathrm{Y}_{1}=$ Drug Release, and $\mathrm{Y}_{2}=$ Entrapment efficiency.

Batch designs in $3^{2}$ Factorial design

Table 1: Table for batch design

\begin{tabular}{llll}
\hline Levels & $\mathbf{- 1}$ & $\mathbf{0}$ & $\mathbf{+ 1}$ \\
\hline Chitosan $(\%)$ & 1 & 1.5 & 2 \\
Tween-20 (ml) & 0.5 & 1.0 & 1.5 \\
\hline
\end{tabular}

Design of responses

Table 2: Table for Responses design

\begin{tabular}{ll}
\hline Chitosan concentrations $\mathbf{X}_{\mathbf{1}}$ & Tween-20 concentrations $\mathbf{X}_{\mathbf{2}}$ \\
\hline-1 & -1 \\
-1 & 0 \\
-1 & +1 \\
0 & -1 \\
0 & 0 \\
0 & +1 \\
+1 & -1 \\
+1 & 0 \\
+1 & +1 \\
\hline
\end{tabular}

\section{Batch formulation according to $\mathbf{3}^{2}$ factorial design}

Table 3: Table for the formulation of batches according to $3^{2}$ factorial design

\begin{tabular}{lll}
\hline S. No. & Chitosan (\%) & Tween-20 (ml) \\
\hline 1 & 1 & 0.5 \\
2 & 1 & 1.0 \\
3 & 1 & 1.5 \\
4 & 1.5 & 0.5 \\
5 & 1.5 & 1.0 \\
6 & 1.5 & 1.5 \\
7 & 2 & 0.5 \\
8 & 2 & 1.0 \\
9 & 2 & 1.5 \\
\hline
\end{tabular}

Optimization of chitosan and tween-20 concentration

Table 4: Optimization of chitosan and tween-20 for gefitinib microspheres

\begin{tabular}{lllll}
\hline S. No. & Formulation code & Chitosan concentration (mg) & $\begin{array}{l}\text { Tween-20 concentration } \\
(\mathbf{m l})\end{array}$ & $\begin{array}{l}\text { Temperatures } \\
\left({ }^{\circ} \mathbf{C}\right)\end{array}$ \\
\hline 1 & & & $\begin{array}{l}\text { Feed Rate of injection } \\
(\mathbf{m l} / \mathbf{m i n})\end{array}$ \\
2 & GCM-1 & 1 & 0.5 & $60-70$ \\
3 & GCM-2 & 1.5 & 0.5 & $60-70$ \\
4 & GCM-3 & 2 & 0.5 & $60-70$ \\
5 & GCM-4 & 1 & 1 & $70-80$ \\
6 & GCM-5 & 1.5 & 1 & $70-80$ \\
7 & GCM-6 & 2 & 1 & $70-80$ \\
8 & GCM-7 & 1 & 1.5 & 1 \\
9 & GCM-8 & 1.5 & 1.5 & 1 \\
\hline
\end{tabular}

- GCM = Gefitinib Chitosan Microspheres, The Percent Entrapment Efficiency and Particle Size Analysis will be done for selecting the bestoptimized formulation. 
Table 5: Percent entrapment efficiency and particle size analysis of gefitinib-chitosan microspheres

\begin{tabular}{llll}
\hline S. No. & Formulation code & Entrapment efficiency (\%) & Particle size ( $\boldsymbol{\mu m})$ \\
\hline 1 & GCM-1 & $29.45 \pm 1.2$ & 11.236 \\
2 & GCM-2 & $43.87 \pm 0.87$ & 11.698 \\
3 & GCM-3 & $69.69 \pm 0.64$ & 12.765 \\
4 & GCM-4 & $72.66 \pm 0.10$ & 13.863 \\
5 & GCM-5 & $79.87 \pm 1.2$ & 14.442 \\
6 & GCM-6 & $29.38 \pm 0.69$ & 10.720 \\
7 & GCM-7 & $50.38 \pm 0.87$ & 11.687 \\
8 & GCM-8 & $68.29 \pm 1.0$ & 12.754 \\
9 & GCM-9 & $68.29 \pm 1.0$ & 11.798 \\
\hline
\end{tabular}

Each data represents $\pm \mathrm{SD},(\mathrm{n}=3)$

\section{Optimization of temperature and speed}

Table 6: Optimization of temperature and speed for the formulation

\begin{tabular}{|c|c|c|c|c|c|c|}
\hline Formulation code & $\begin{array}{l}\text { Temperature } \\
\left({ }^{\circ} \mathrm{C}\right)\end{array}$ & $\begin{array}{l}\text { Speed } \\
\text { (rpm) }\end{array}$ & $\begin{array}{l}\text { Chitosan } \\
\text { Concentration (\%) }\end{array}$ & $\begin{array}{l}\text { Tween } 20 \\
\text { (ml) }\end{array}$ & $\begin{array}{l}\text { Entrapment efficiency } \\
(\%)\end{array}$ & $\begin{array}{l}\text { Particle size } \\
(\mu \mathrm{m})\end{array}$ \\
\hline GCM-10 & 60 & 700 & 1.5 & 1 & $52.94 \pm 0.8$ & 12.389 \\
\hline GCM-11 & 65 & 700 & 1.5 & 1 & $59.92 \pm 0.7$ & 12.830 \\
\hline GCM-12 & 70 & 700 & 1.5 & 1 & $65.59 \pm 0.64$ & 13.927 \\
\hline GCM-13 & 60 & 1200 & 1.5 & 1 & $79.93 \pm 0.58$ & 13.934 \\
\hline GCM-14 & 65 & 1200 & 1.5 & 1 & $83.72 \pm 0.5$ & 14.010 \\
\hline GCM-15 & 70 & 1200 & 1.5 & 1 & $80.34 \pm 0.98$ & 13.211 \\
\hline GCM-16 & 60 & 1800 & 1.5 & 1 & $71.54 \pm 1.1$ & 12.178 \\
\hline GCM-17 & 65 & 1800 & 1.5 & 1 & $45.76 \pm 0.58$ & 11.892 \\
\hline GCM-18 & 70 & 1800 & 1.5 & 1 & $49.75 \pm 0.08$ & 11.592 \\
\hline
\end{tabular}

From the above-mentioned data, formulations of Gefitinib Chitosan Microspheres are prepared at the temperature optimized to be $65{ }^{\circ} \mathrm{C}$ and speed was optimized at $1200 \mathrm{rpm}$.

\section{Various process parameters selection}

Table 7: Various process parameters selected during optimization

\begin{tabular}{lll}
\hline S. No. & Process parameters & Optimized values \\
\hline 1 & Chitosan concentration & $1.5 \mathrm{gm}$ \\
2 & Tween-20 concentration & 1 \\
3 & Temperature & 65 \\
4 & Rotation Speed & $1200 \mathrm{rpm}$ \\
\hline
\end{tabular}

Table 8: Final ingredients for microsphere preparation

\begin{tabular}{llc}
\hline S. No. & Ingredients & Quantity \\
\hline 1 & Chitosan & 1.5 \\
2 & Tween-20 & $1 \mathrm{ml}$ \\
3 & $25 \%$ Gluteraldehyde & $0.5 \mathrm{ml}$ \\
4 & $5 \%$ Acetic Acid & $20 \mathrm{ml}$ \\
5 & Gefitinib & $100 \mathrm{mg}$ \\
6 & Petroleum ether & $5 \mathrm{ml}$ \\
7 & Heavy Liquid Paraffin & $500 \mathrm{ml}$ \\
8 & N-Hexane & $200 \mathrm{ml}$ \\
9
\end{tabular}

Particle size analysis was done by optical microscopy having least count

From the above-mentioned data, the Formulation Code GCM-5 shows maximum Percent Entrapment Efficiency $(79.87 \pm 1.2)$ and Particle Size $(14.442 \mu \mathrm{m})$ was selected to be best-optimized formulation.

\section{Final optimized formulation table}

For the preparation of Gefitinib-chitosan microspheres, the following ingredients were taken as in optimized concentrations:

\section{Characterization of chitosan microspheres}

\section{Yields of production}

The amounts of these microspheres obtained of each batch were weighed, and the percentage yield was calculated by taking into the consideration of the weight of drug and weight of polymer
[5]. The Percentage Yield was calculated by using the given formula:

$\%$ Yield of Production $=$ Practical Yield $/$ Theoretical Yield $\times 100$

These calculations were done in triplicate $(n=3)$, and the mean was calculated.

\section{Swelling index}

The degree of swelling of the optimized formulation was calculated with little modifications [6]. The swelling ability of the microparticles to swell them in Phosphate Buffer $\mathrm{pH} 6.8$ was determined by immersing $100 \mathrm{mg}$ of microspheres in little excess of Phosphate Buffer pH 6.8 in 16 ml capacities of Franz-Diffusion Cell for $24 \mathrm{~h}$ and then washed. The formula used for degree of swelling:

$\alpha=\mathrm{W}_{\mathrm{s}}-\mathrm{W}_{0} / \mathrm{W}_{0}$ 
Table 9: Yields of production of the optimized formulation of gefitinib chitosan microspheres

\begin{tabular}{lll}
\hline S. No. & Formulation code & Production yield (\%) \\
\hline 1 & GCM-5 & 48 \\
\hline
\end{tabular}

Table 10: Degree of swelling of optimized formulations containing chitosan microspheres

\begin{tabular}{lll}
\hline S. No. & Formulation batch & Degree of swelling \\
\hline 1 & GCM-5 & 45 \\
\hline
\end{tabular}

\section{Percent entrapment efficiency}

Gefitinib Chitosan Microspheres were crushed and suspended in 10 $\mathrm{ml}$ methanol to extract the drug from microspheres. After $24 \mathrm{~h}$, the formulation was then centrifuged to $700 \mathrm{rpm}$, and the supernatant was separated [7]. This supernatant was assayed in UV Spectrophotometer (Shimadzu 1800) at $260 \mathrm{~nm}$. The blank solvent was taken as methanol.

Percent Entrapment Efficiency $=\mathrm{W} \alpha-\mathrm{Ws} \times 100$

$\mathrm{W} \alpha$

$\mathrm{W} \alpha=$ drug added in the formulation, $\mathrm{Ws}=$ drug in the supernatant.

\section{Drug loading efficiency}

Drug Loading Efficiency was also calculated by the above-mentioned process, and the supernatant was being assayed under UV
Spectrophotometer under $260 \mathrm{~nm}$. Blank solution was taken as methanol [8].

Drug Loading Efficiency $=\mathrm{W} \alpha-\mathrm{Ws} \times 100$

$\mathrm{W} \alpha-\mathrm{Ws}+\mathrm{Wp}$

Where; $\mathrm{Wp}=$ Weight of chitosan polymer

\section{Scanning electron microscopy}

Scanning Electron Photomicrographs of a formulation containing Gefitinib-Chitosan Microsphere was obtained by using Scanning Electron Microscope (Jeol, JSM 5600, Japan). Into this process, the microspheres in little quantity were spread on the aluminum stub [9]. Then this was placed under the chamber of Scanning Electron Microscope at an acceleration voltage of $15.00 \mathrm{kV}$ EHT under the magnification of $88 \mathrm{X}$, and the detector SE1 has used The photomicrograph of this sample is obtained.

Table 11: Percent entrapment efficiency of optimized formulations containing gefitinib chitosan microspheres

\begin{tabular}{lll}
\hline S. No. & Formulation batch & Entrapment efficiency (\%) \\
\hline 1 & GCM-5 & $79.87 \pm 0.12$ \\
\hline
\end{tabular}

Table 12: Drug loading efficiency of optimized formulations containing gefitinib chitosan microspheres

\begin{tabular}{lll}
\hline S. No. & Formulation batch & Drug loading efficiency (\%) \\
\hline 1 & GCM-5 & $68.23 \pm 0.56$ \\
\hline
\end{tabular}

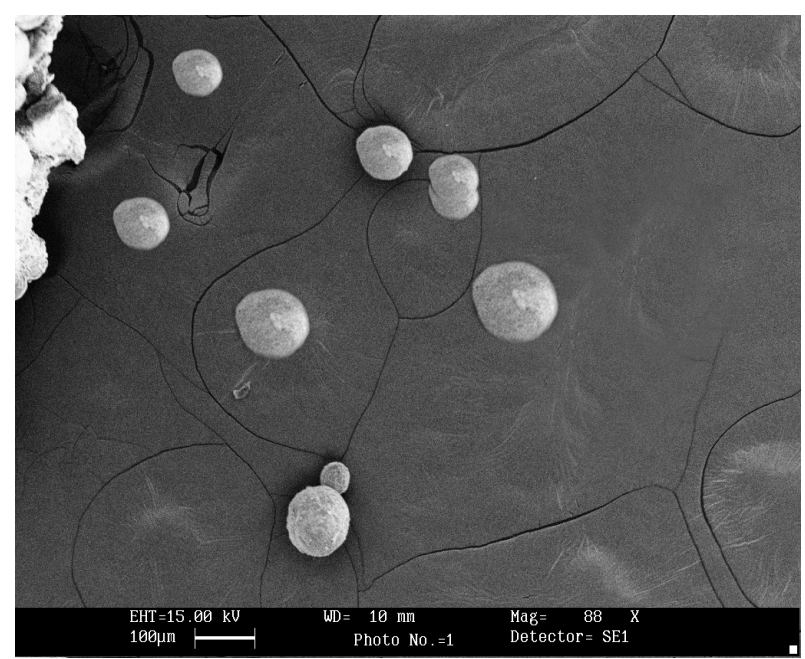

Fig. 2: SEM of gefitinib chitosan microspheres

\section{Particle size determination}

Determination of particle size of an optimized formulation containing Gefitinib-Chitosan Microspheres was obtained by appropriate hydration using $\mathrm{pH} 6.8(5 \mathrm{ml})$ with manual shaking for 5 min through Horiba Nano Particle Analyzer at NDDS Lab, VNS Faculty of Pharmacy, Bhopal (M. P.). The result obtained was as follows: 
Table 13: Particle size analysis of optimized formulation gefitinib chitosan microspheres

\begin{tabular}{lll}
\hline S. No. & Formulation batch & Particle size ( $\mu \mathrm{m})$ \\
\hline 1 & GCM-5 & 14.628 \\
\hline
\end{tabular}

2017.09.19 15:41:15

NDDS Lab

VNS Faculty of Pharmacy, Bhopal

\section{6.nsz}

Measurement Results

Date

Measurement Type

Sample Name

Scattering Angle

Temperature of the holder

T\% before meas.

Viscosity of the dispersion medium

Form Of Distribution

Representation of result

Count rate

Calculation Results
* Tuesday,September 19,2017 15:41:15 PM

: Particle Size

- F Microsphere

90

$: 25.0^{\circ} \mathrm{C}$

: 18602

: $0.894 \mathrm{mPa} \cdot \mathrm{s}$

: Standard

: Scattering Light Intensity

: $822 \mathrm{kCPS}$

\begin{tabular}{|c|c|c|c|c|}
\hline Peak No. & S.P.Area Ratio & Mean & S.D. & Mode \\
\hline 1 & 1.00 & $223 \_4 \mathrm{~nm}$ & $18.4 \mathrm{~nm}$ & $218.2 \mathrm{~nm}$ \\
\hline 2 & - & $-\mathrm{nm}$ & $-\mathrm{nm}$ & $=\mathrm{nm}$ \\
\hline 3 & - & $-\mathrm{nm}$ & $-\mathrm{nm}$ & $--\mathrm{nm}$ \\
\hline Total & 1.00 & $223 \_4 \mathrm{~nm}$ & $18.4 \mathrm{~nm}$ & $218.2 \mathrm{~nm}$ \\
\hline
\end{tabular}

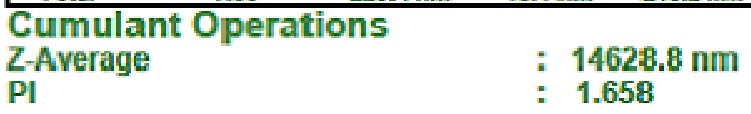
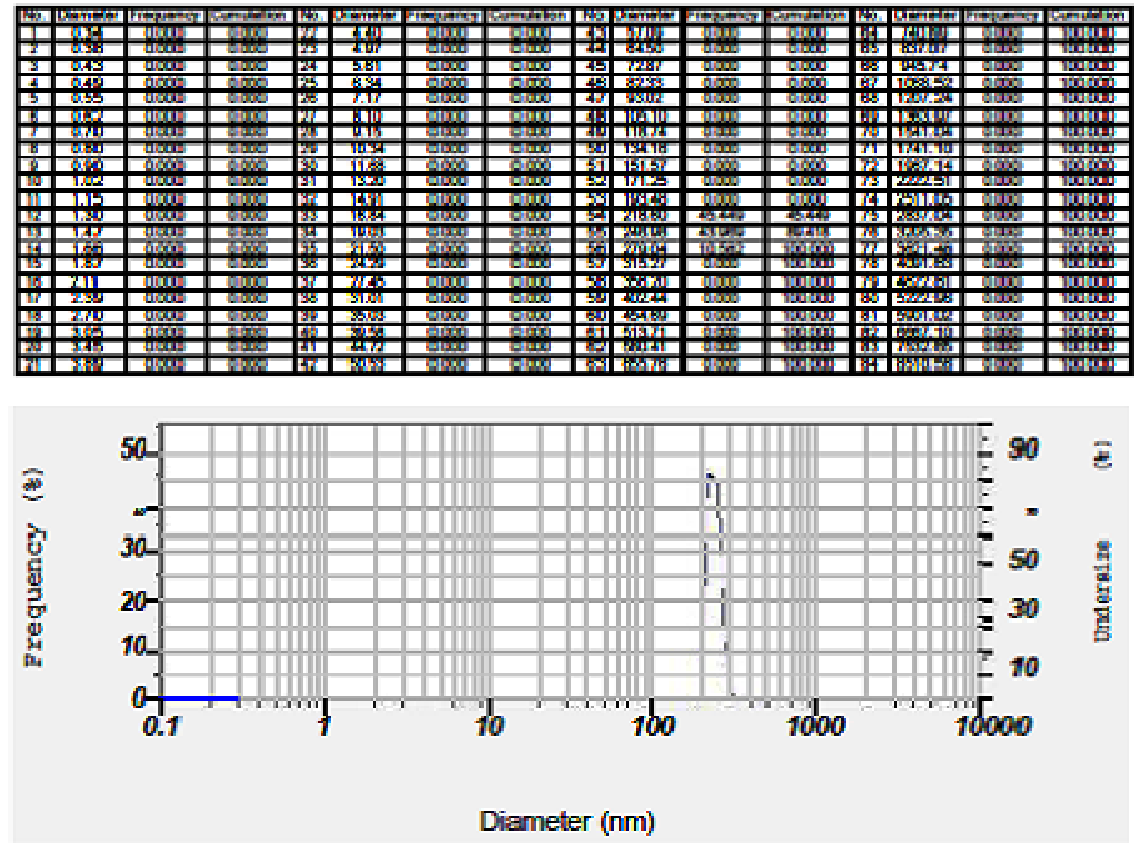

Fig. 3: Particle size determination of gefitinib chitosan microspheres

Zeta potential measurement

Zeta Potential is the representative of positive charge. The Zeta Potential measurement of these optimized formulations was measured by Horiba Nano Particle Analyzer in NDDS Lab, VNS
Faculty of Pharmacy, Bhopal (M. P.) It involves the preparation of a dispersion of microspheres in distilled water.

Afterwords, this dispersion mixture was filled in Zeta Cell and placed in an analyzer that will determine the Zeta Potential. 
Table 14: Zeta potential measurement of an optimized formulation containing gefitinib chitosan microsphere

\begin{tabular}{lll}
\hline S. No. & Formulation batch & Zeta-potential (mV) \\
\hline 1 & GCM-5 & $-35.2 \mathrm{mV}$ \\
\hline
\end{tabular}

\section{NDDS Lab}

VNS Faculty of Pharmacy, Bhopal

\subsubsection{5:47:26}

\section{HORIBA NANO PARTICLE ANALYZER}

\section{Measurement Results}
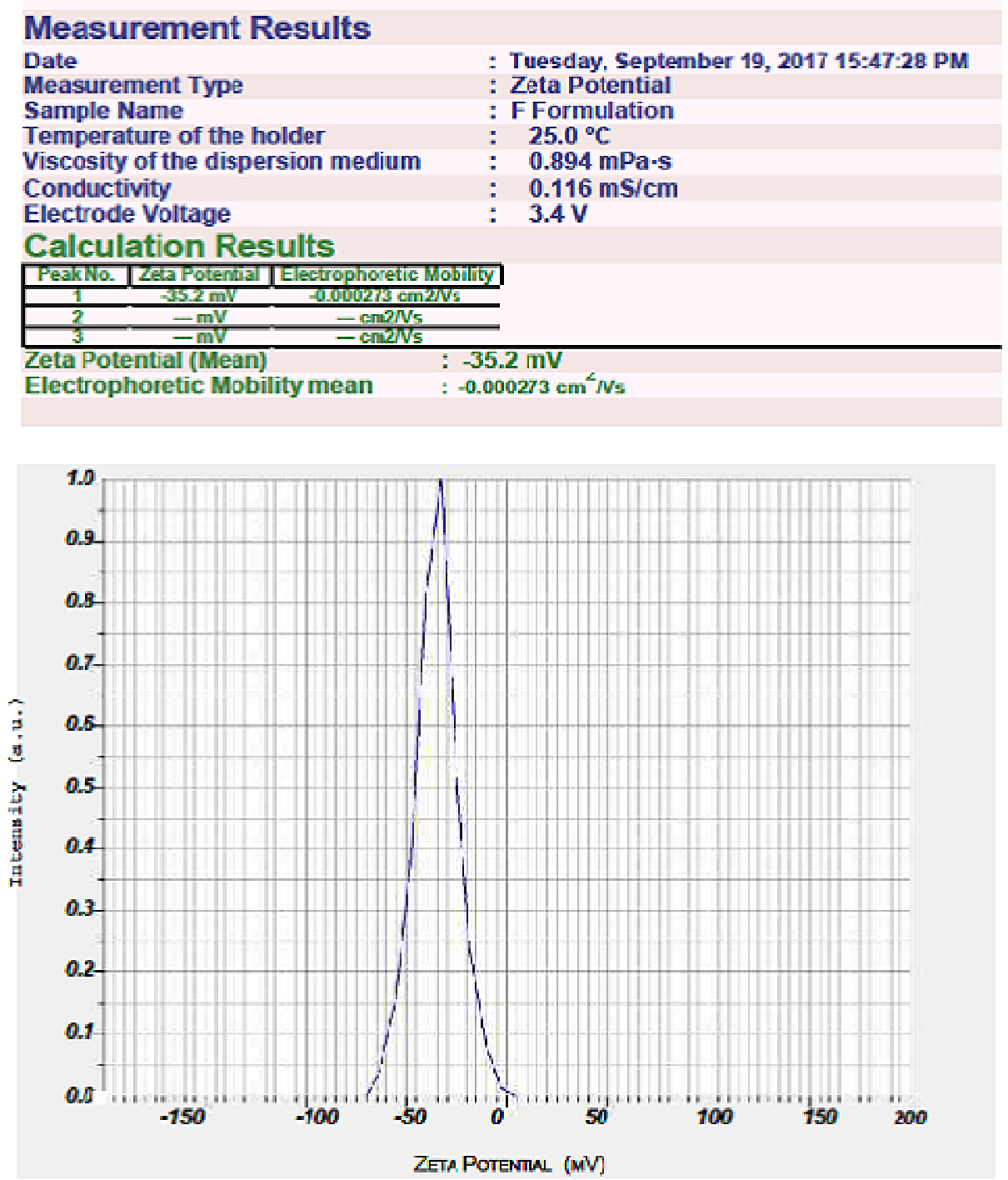

Fig. 4: Zeta potential measurement of gefitinib chitosan microspheres

\section{In-vitro mucoadhesion strength measurement}

A strip of the mucoadhesive skin of Sheep or Goat was mounted on a glass slide with a fixative adhesion. Numbers of counted GefitinibChitosan Microspheres were placed on the mucoadhesive membrane after washing the membrane with distilled water and then PBS $\mathrm{pH}$ 6.8 for 5 min continuously. The glass slide was then incubated for 15 min in a desiccator at $80 \% \mathrm{RH}$ to allow the polymer for interaction with the membrane that placed on the cell and was attached to the assembly inclined at $45^{\circ} \mathrm{C}$ [10]. Then PBS pH 6.8 was circulated on the cell over the microspheres and skin at the rate of $2 \mathrm{ml} / \mathrm{min}$ from the burette. This was then subjected for washing and collected at different time intervals, and a number of capsules were drained off and counted by using haematocytometer chamber under an optical microscope.

Following equation gives the adhesion number as:

$$
\mathrm{N}_{\mathrm{a}}=\mathrm{N} / \mathrm{N}_{\mathrm{o}} \times 100
$$

Where; $\mathrm{N}_{\mathrm{a}}=$ Adhesion Number, $\mathrm{N}_{\mathrm{o}}=$ Number of Microspheres present in that area, $\mathrm{N}=$ Number of Microspheres attached to the mucosa after washing. 
Table 15: In-vitro mucoadhesion test of a formulation containing gefitinib chitosan microspheres

\begin{tabular}{lll}
\hline S. No. & Time (h) & In-vitro mucoadhesion (\%) \\
\hline 1 & 1 & $87.82 \pm 44$ \\
2 & 2 & $79.47 \pm 83$ \\
3 & 4 & $67.81 \pm 78$ \\
4 & 6 & $56.70 \pm 84$ \\
5 & 7 & $23.56 \pm 73$ \\
\hline
\end{tabular}

\section{In-vitro drug release studies}

In-vitro release drug release studies were performed in phosphate buffer solution $\mathrm{pH} 6.8$ by using 6 Station USP Dissolution Apparatus (Basket type) at $37 \pm 0.5{ }^{\circ} \mathrm{C}$ and $50 \mathrm{rpm}$ (Veego, VDA-6DR, India). Formulations containing Gefitinib Chitosan Microspheres $(100 \mathrm{mg})$ were tested in $900 \mathrm{ml}$ of Phosphate Buffer Solution pH 6.8. $1 \mathrm{ml}$ sample has been withdrawn in $10 \mathrm{ml}$ volumetric flask at fixed time intervals $(1,2,3,4,5, \ldots 24,48 \mathrm{~h}$ respectively), and replaced with fresh $1 \mathrm{ml}$ of Phosphate Buffer $\mathrm{pH} 6$ to maintain sink conditions [11]. These $1 \mathrm{ml}$ withdrawn samples are then diluted with the same solvent up to $10 \mathrm{ml}$ mark in a volumetric flask. Then, these samples are scanned at $254 \mathrm{~nm}$ using Shimadzu 1800 UVSpectrophotometer. The drug release kinetics models are applied to determine the cumulative amount of drug release at each time and graph has been plotted.

Table 16: In-vitro drug release studies of optimized formulation of gefitinib chitosan microspheres

\begin{tabular}{|c|c|c|c|c|c|}
\hline S. No. & Time (h) & Absorbance & Concentrations $(\mu \mathrm{g} / \mathrm{ml})$ & Amount (mg/ml) & Drug release (\%) \\
\hline 1 & 0 & 0 & 0 & 0 & 0 \\
\hline 2 & 6 & 0.056 & 2.05 & 18.45 & 30.75 \\
\hline 3 & 12 & 0.08 & 3.25 & 29.25 & 48.75 \\
\hline 4 & 24 & 0.122 & 5.35 & 48.15 & 80.25 \\
\hline 5 & 36 & 0.138 & 6.15 & 55.35 & 92.25 \\
\hline 6 & 48 & 0.143 & 6.4 & 57.6 & 96 \\
\hline 7 & 60 & 0.145 & 6.5 & 58.5 & 97.5 \\
\hline 8 & 72 & 0.146 & 6.55 & 58.95 & 98.25 \\
\hline
\end{tabular}

\section{Drug release kinetics}

Release kinetics studies are more useful for prediction of different modified release dosage forms. These release patterns help to define the time and rate of release of drug to be followed. Different mathematical models used to predict the release patterns in a definite manner. The selection of best release model based on the highest regression value $\left(\mathrm{R}^{2}\right)$, ANOVA and MANOVA, etc. [12]. The different models are applied, and the best statistical model would be selected as Korsemeyer-Pappas Model as it has given the highest coefficient of determinants $\left(\mathrm{R}^{2}\right.$ value).

Table 17: Korsemeyer-pappas model of In-vitro drug release for gefitinib chitosan microspheres

\begin{tabular}{llllll}
\hline $\begin{array}{l}\text { Time } \\
(\mathbf{h}) \mathbf{T}\end{array}$ & $\begin{array}{l}\text { Log time } \\
\mathbf{l o g}(\mathbf{t})\end{array}$ & $\begin{array}{l}\text { Concentration } \\
(\boldsymbol{\mu g} / \mathbf{m l})\end{array}$ & $\begin{array}{l}\text { Amount } \\
(\mathbf{m g} / \mathbf{m l})\end{array}$ & $\begin{array}{l}\text { Cumulative drug release } \\
(\mathbf{\%})\end{array}$ & $\begin{array}{l}\text { Log of cumulative drug release } \\
(\mathbf{\%})\end{array}$ \\
\hline 0 & 0 & 0 & 0 & 0 & 0 \\
6 & 0.7781 & 2.05 & 18.45 & 30.75 & 1.4878 \\
12 & 1.0791 & 3.25 & 29.25 & 48.75 & 1.6879 \\
24 & 1.3802 & 5.35 & 48.15 & 80.25 & 1.9044 \\
36 & 1.5563 & 6.15 & 55.35 & 92.25 & 1.9649 \\
48 & 1.6812 & 6.4 & 57.6 & 96 & 1.9822 \\
60 & 1.7781 & 6.5 & 58.5 & 97.5 & 1.9890 \\
72 & 1.8573 & 6.55 & 58.95 & 98.25 & 1.9923 \\
\hline
\end{tabular}

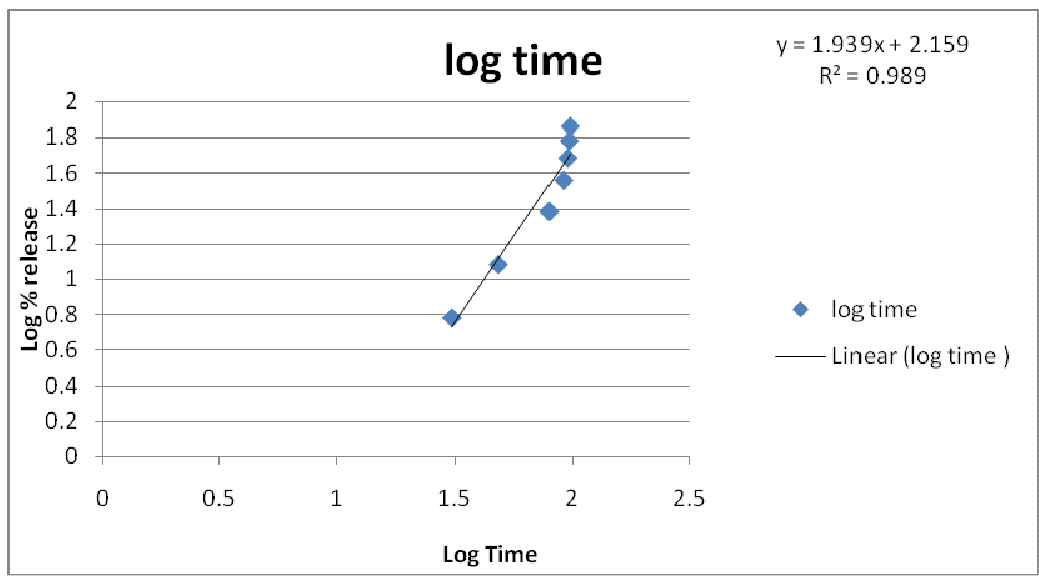

Fig. 5: Korsemeyer pappas model 
Table 18: In vitro drug release of formulation GCM-1 to GCM-9

\begin{tabular}{|c|c|c|c|c|c|c|c|c|c|c|}
\hline \multirow[t]{2}{*}{ Time (h) } & \multicolumn{5}{|c|}{ \% Cumulative drug release } & \multirow[b]{2}{*}{ GCM-5 } & \multirow[b]{2}{*}{ GCM-6 } & \multirow[b]{2}{*}{ GCM7 } & \multirow[b]{2}{*}{ GCM-8 } & \multirow[b]{2}{*}{ GCM-9 } \\
\hline & Pure drug & GCM-1 & GCM-2 & GCM-3 & GCM-4 & & & & & \\
\hline 0 & 0 & 0 & 0 & 0 & 0 & 0 & 0 & 0 & 0 & 0 \\
\hline 6 & 34.44 & 24.45 & 34.56 & 44.68 & 30.12 & 30.75 & 22.97 & 24.56 & 23.45 & 20.17 \\
\hline 12 & 68.67 & 51.45 & 39.87 & 51.67 & 49.81 & 48.75 & 36.89 & 29.94 & 29.55 & 25.50 \\
\hline 24 & 96.81 & 60.26 & 55.79 & 60.98 & 61.87 & 80.25 & 45.65 & 32.76 & 32.86 & 39.81 \\
\hline 36 & 97.45 & 65.58 & 61.64 & 74.58 & 69.43 & 92.25 & 58.11 & 44.98 & 40.58 & 41.86 \\
\hline 48 & 97.49 & 79.54 & 72.89 & 82.98 & 72.98 & 96 & 62.64 & 54.81 & 49.94 & 50.67 \\
\hline 60 & 97.61 & 80.77 & 88.81 & 88.78 & 79.65 & 97.5 & 69.69 & 59.99 & 50.76 & 61.81 \\
\hline 72 & 97.44 & 82.84 & 91.92 & 91.98 & 81.23 & 98.25 & 72.47 & 71.76 & 68.98 & 64.62 \\
\hline
\end{tabular}

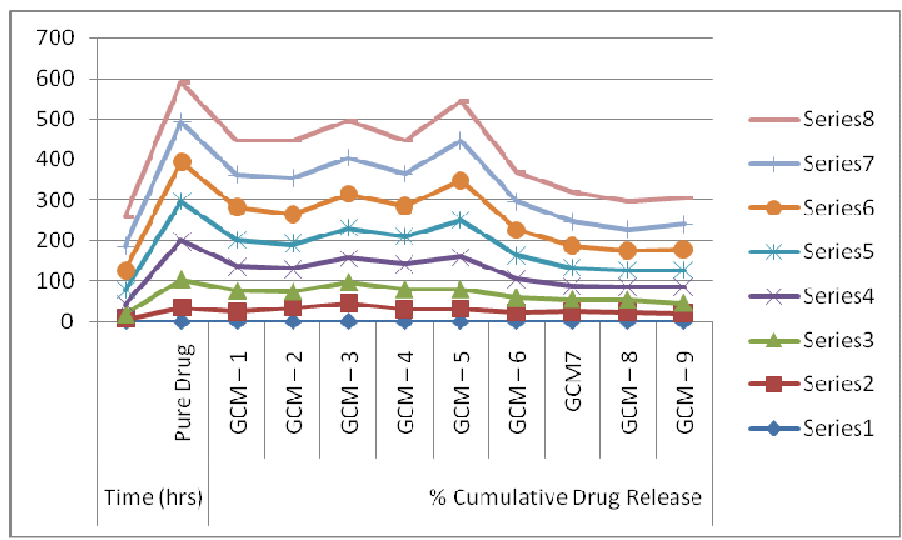

Fig. 6: Curve representing percent cumulative drug release of all formulations containing gefitinib-chitosan microspheres

\section{Drug-excipient studies by differential scanning calorimetry}

Differential Scanning Calorimetry is that thermal analysis procedure by which we can measure the interaction of the drug with the polymer before and after the formulation at high temperatures. This will also show the thermal degradation resulted if any. This analysis was done by SOPS, RGPV, Bhopal (M. P.) by the process of PerkinElmer Thermal Analysis. Standards of Indium were taken for calibration purpose of temperature and enthalpy scale. Hermetically sealed samples in aluminum pans are heated at a constant rate of temperature of $30.00{ }^{\circ} \mathrm{C} / \mathrm{min}$ with ranges from $30.00-350.00^{\circ} \mathrm{C}$ at $40.00{ }^{\circ} \mathrm{C} / \mathrm{min}$ Purging Nitrogen was used at a flow rate of $100 \mathrm{ml} / \mathrm{ml}$ for maintaining the inert environment.

\section{DSC of gefitini}

The heat flow during the endothermic process was observed at-34 $\mathrm{mW}$. The temperature was sharply recorded at $205{ }^{\circ} \mathrm{C}$ which was approximate near to the melting point of Gefitinib itself.

\section{DSC of chitosan}

In the case of chitosan, the endothermic peak was observed at-3 $\mathrm{mW}$, and the broad peak was obtained at $108^{\circ} \mathrm{C}$.

\section{DSC of gefitinib-chitosan microsphere}

The microspheres prepared by Gefitinib and Chitosan combination shows the endothermic peak in a positive direction at $2.3 \mathrm{~mW}$, and the temperature was recorded at $92^{\circ} \mathrm{C}$.

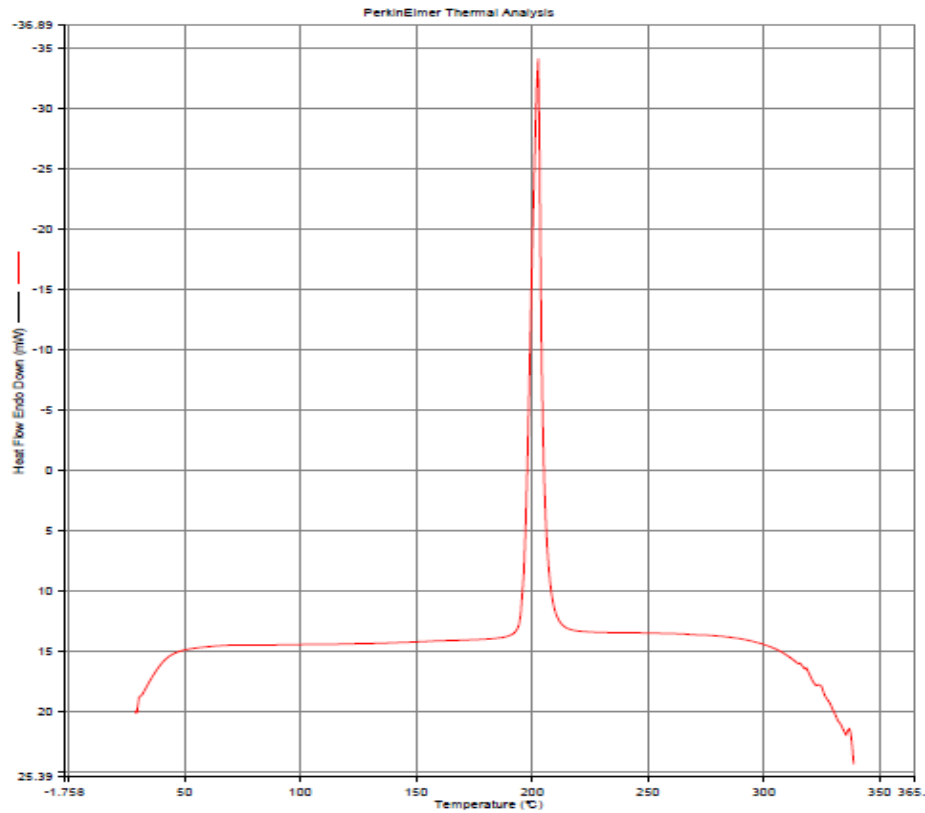

Fig. 7: DSC curve of drug (Gefitinib) 


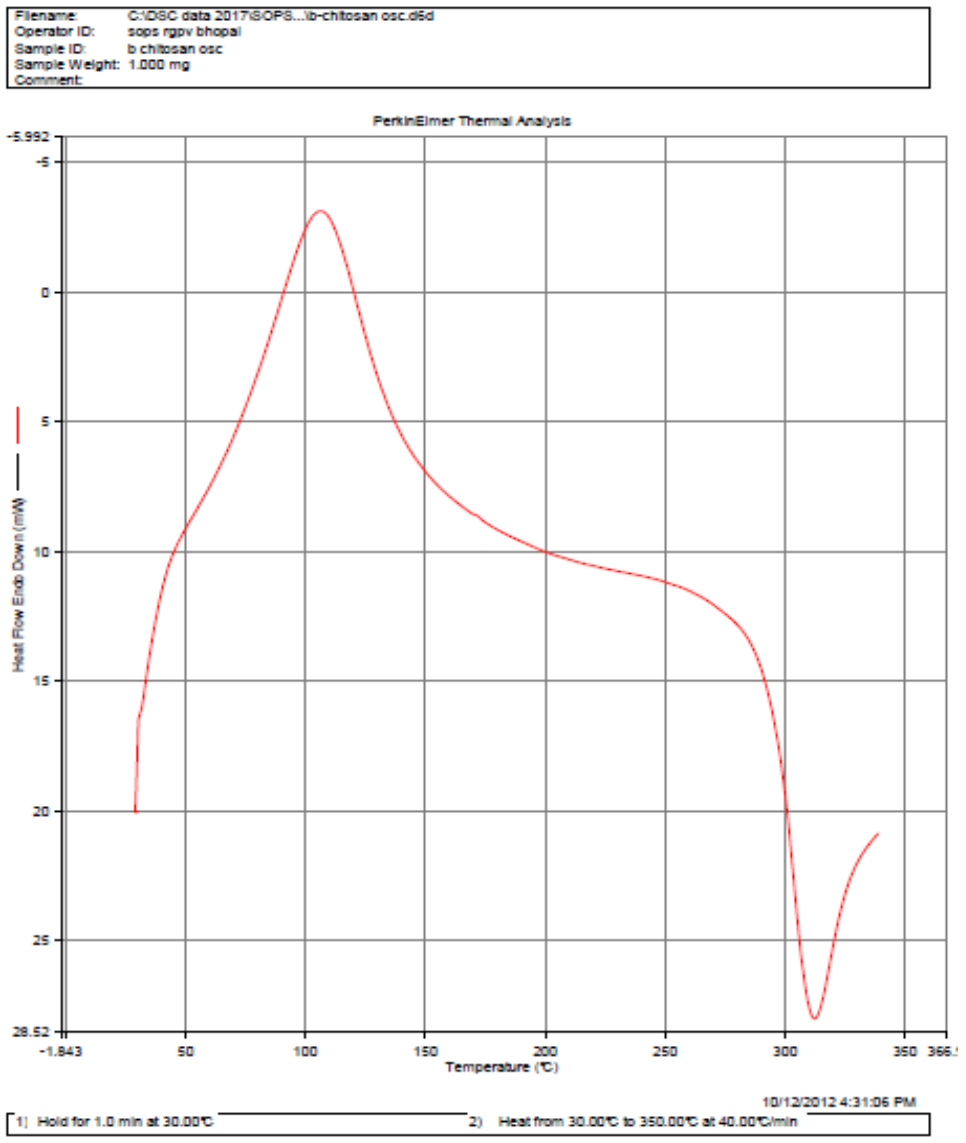

Fig. 8: DSC of chitosan

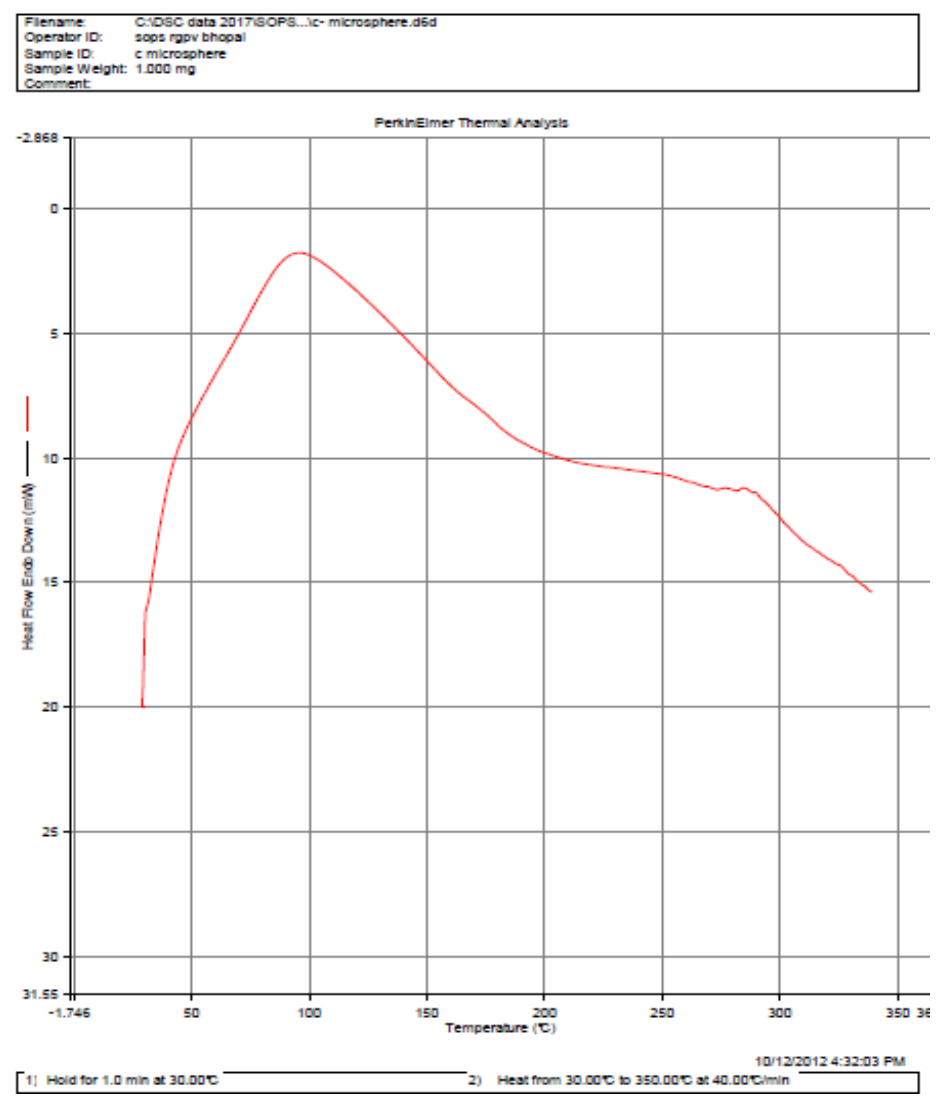

Fig. 9: DSC of gefitinib-chitosan microspheres 
Table 19: Table for DSC analysis

\begin{tabular}{llll}
\hline S. No. & Endothermic peaks $(\mathbf{m W})$ & Temperature $\left({ }^{\circ} \mathbf{C}\right)$ & Peak types \\
\hline Gefitinib & -34 & 205 & Sharp \\
Chitosan & -3 & 108 & Broad \\
Microspheres & 2.3 & 92 & Broad \\
\hline
\end{tabular}

\section{RESULTS AND DISCUSSION}

\section{Differential scanning calorimetric studies}

According to these DSC graphs of Gefitinib, Chitosan and microspheres containing a combination of these two states that, there is no deviation into the melting point of gefitinib $\left(197^{\circ} \mathrm{C}\right)$ from the chitosan and both the graphs shows significant peaks in this analysis. Firstly, the drug is in crystalline form, but as the microspheres are prepared by chitosan polymer, peak shifted towards the right side and slightly changes its nature to amorphous form due to chemical interactions and high temperatures. But overall, the drug doesn't have any interactions with chitosan.

\section{Yield of production}

The percentage yield of the batches prepared by Gefitinib-Chitosan Microspheres was determined, and the optimized yield of production was found to be $45 \%$.

\section{Scanning electron microscopy}

The morphological characteristics of chitosan-based microspheres of Gefitinib were determined by photomicrographs obtained by Scanning Electron Microscopy under 88 X. The SEM image of these microspheres also exhibits a somewhat rough texture which is due to the feeding of chitosan solution and reaction between the solvent system and chitosan solution. The SEM image also confirms that there is not any residual content of drug left on the surface and no surface was ruptured during the preparation of microspheres. All the microspheres are nearly smooth and circular in shape. The drug embedded successfully into the core content. The particle size of the optimized formulation was then further determined to confirm the size of each microsphere. Later the drug delivery system has been decided.

\section{Particle size determination}

The particle size determination of Gefitinib-chitosan microspheres was performed by Horiba Nano Particle Analyzer which has given the average particle size of $233.4 \mathrm{~nm}$. The Z Average was found to be 14628.28 and PI is 1.658.

\section{Percentage entrapment efficiency}

The percentage entrapment efficiencies of Gefitinib-Chitosan Microspheres were determined under UV Spectrophotometer and later were optimized to be $79.87 \pm 0.12 \%$.

\section{Drug loading efficiencies}

The Drug Loading Efficiencies of Gefitinib-Chitosan Microspheres were determined by UV Spectrophotometer by using the given formula. Optimized formulation shows the Percent Drug Loading Efficiency of $68.23 \pm 0.56 \%$.

\section{Degree of swelling}

Chitosan having the swelling capacity will tend to swell the microsphere and rupture the cell wall that tends to show burst release effect. So to control and identify how much bursting and swelling is there, swelling parameter was studied. The degree of swelling was obtained to be $45 \%$.

\section{Zeta potential measurement}

Zeta Potential Measurement is an important parameter essential for the prediction of particle's stability. Higher the zeta potential value, higher will be the repulsive force between particles that resulted in less aggregation. The zeta potential measurement of the GefitinibChitosan Microspheres were found to be- $35.2 \mathrm{~mW}$.

\section{In-vitro mucoadhesive strength measurement}

Mucoadhesive is the special characteristic property of chitosan microspheres that tend to adhere to the mucoadhesive membrane present inside the body cavities. This property decides the drug release pattern of the drug delivery system. The In-vitro mucoadhesive strength measurement was determined for Gefitinib-chitosan microspheres for 1 hour $87.82 \pm 44 \%$ up to $7 \mathrm{~h}$ will be $23.56 \pm 73 \%$ respectively.

\section{In-vitro drug release studies}

For determination of the release patterns and decide either the formulation is able to show sustained release, prolonged release, burst release, etc; the In-vitro drug release studies were performed. This is the main criteria for this whole research work to produce sustained release microspheres that reduce the dosage frequency of the drug. The percent cumulative In-vitro drug release was determined to be $98.25 \%$ for $72 \mathrm{~h}$. The results indicated that Gefitinib-chitosan microspheres were prepared by solvent evaporation technique stat the promising controlled release for drug delivery system.

\section{Drug release kinetics studies}

All the formulations of GCM-1 to GCM-18 are subjected to determine the Percent Cumulative Drug Release and fitted into different kinetics release models from which, Formulation GCM-5 resulted in following Korsemeyer-Pappas Model for the drug delivery of Gefitinib-Chitosan Microspheres that have the highest regression value of $\mathrm{R}^{2}=0.989$.

\section{CONCLUSION}

From the above thesis work, it has been concluded that microspheres can be prepared by solvent evaporation technique by varying the concentration of chitosan and tween-20. Chitosan used in this work is of $85 \%$ degree of deacetylation. $25 \%$ solution of Glutaraldehyde is suitable for the formulation of these microspheres. The optimized temperature was selected as $65^{\circ} \mathrm{C}$, and the rotation speed was taken as $1200 \mathrm{rpm}$.

\section{Drug-excipient compatibility studies}

This was done by Fourier transform infrared spectroscopy and Differential Scanning Calorimetry. FTIR states that there is no interaction between Gefitinib and Chitosan in the formulation. Little similar peaks are observed due to certain process parameters. DSC curves show that the drug is in crystalline form changes to amorphous form when combines with chitosan as the curve shifts towards right.

\section{Scanning electron microscopy}

This was done under $88 \mathrm{X}$ magnification and confirms that there is no residual content left over the surface of the drug, and the smooth and circular shape was obtained.

\section{Particle size determination}

Horiba Nano Particle Size Analyzer was used for the particle size determination, and the size was found to be in the micro range. The $\mathrm{Z}$ Average particle size was found to be $14.628 \mu \mathrm{m}$, and PI is 1.658 . This size range is more useful and suitable for the drug delivery through pulmonary route Gravitational Sedimentation.

\section{Percent entrapment efficiency}

This was obtained and optimized to be $79.87 \pm 0.12 \%$. That the drug loaded in a successful manner.

\section{Drug loading efficiency}

The Percent Drug Loading Efficiency of the optimized formulation (GCM-5) was determined to be $68.23 \pm 0.56 \%$. It concludes that 100 
mg of the drug was added into the formulation and out of which $68.23 \pm 0.56 \%$ of the drug has been loaded into the microspheres embedded by chitosan and rest of drug will be present into the supernatant.

\section{Zeta potential measurement}

The obtained value for zeta potential measurement is- $35.2 \mathrm{~mW}$. This concluded that there is a microsphere formed are in separate conditions and does not forms aggregates and non-sticky in nature as higher the zeta potential value, more will be the repulsive force between the particles and less aggregates will be formed.

\section{In-vitro mucoadhesive test}

This was performed and evaluated and the result obtained from this that, chitosan will adhere to skin mucosal membranes for 1 hour $87.82 \pm 44 \%$ up to $7 \mathrm{~h} 23.56 \pm 73 \%$ respectively. This concluded as the chitosan polymer has successfully adhered to the mucoadhesive membrane and acts as a rate controlling polymer for the delivery of drug Gefitinib in a sustained release manner.

\section{In-vitro drug release studies}

The release patterns obtained from this study that the formulation will release the drug in a sustained manner up to $72 \mathrm{~h}$ means ( $3 \mathrm{~d}$ ) successfully. The cumulative percent drug release was obtained as 98.25\%, and the formulation containing drug Gefitinib follows Korsemeyer-Pappas Model for the drug delivery of these Chitosan Microspheres containing Gefitinib. According to this model, the drug will release from the polymeric matrix system in the form of dissolution of drug from the core. To understand the mechanism of drug release, the $60 \%$ of the drug release should be fitted under the equation given by Korsmeyer-Pappas Model.

\section{ACKNOWLEDGMENT}

I would like to express mu gratitude to Mr. Vinay Chandra from Natco Pharma Ltd for providing me Gefitinib as a free gift sample. Also, I am very thankful to Mr. Koushik Nagar for providing me $85 \%$ degree of deacetylated Chitosan from Mumbai.

\section{AUTHORS CONTRIBUTIONS}

All the author have contributed equally

\section{CONFLICT OF INTERESTS}

Declared none

\section{REFERENCES}

1. Learoyd TP, Burrows JL, French E, Seville PC. Chitosan-based spray-dried respirable powders for sustained delivery of terbutaline sulfate. Eur J Pharm Biopharm 2008;68:224-34.

2. Singh MN, Hemant KSY, Ram M, Shivkumar HG. Microencapsulation: a promising technique for controlled drug delivery. Res Pharm Sci 2010;5:65-77.

3. Freiberg S, Zhu XX. Polymer microspheres for controlled drug release. Int J Pharm 2004;282:1-18.

4. Bhavsar MD, Tiwari SB, Amiji MM. Formulation optimization for the nanoparticles-in-microsphere hybrid oral delivery system using factorial design. J Controlled Release 2006;110:422-30.

5. He P, Davis SS, Illum L. Chitosan microspheres prepared by spray drying. Int J Pharm 1999;187:53-65.

6. Genta I, Costantini M, Asti A, Conti B, Montanari L. Influence of glutaraldehyde on drug release and mucoadhesive properties of chitosan microspheres. Carbohydrate Polymers 1998;36:81-8.

7. Agnihotri SA, Mallikarjuna NN, Aminabhavi TM. Recent advances on chitosan-based micro-and nanoparticles in drug delivery. J Controlled Release 2004;100:5-28.

8. Yu X, Yang G, Shi Y, Su C, Liu M, Feng B, Zhao L. Intracellular targeted co-delivery of shMDR1 and gefitinib with chitosan nanoparticles for overcoming multidrug resistance. Int J Nanomed 2015;10:7045.

9. Zhao L, Yang G, Shi Y, Su C, Chang J. Co-delivery of gefitinib and chloroquine by chitosan nanoparticles for overcoming the drug acquired resistance. J Nanobiotechnol 2015;13:57.

10. Zhou X, Yung B, Huang Y, Li H, Hu X, Xiang G, et al. Novel liposomal gefitinib (L-GEF) formulations. Anticancer Res 2012;32:2919-23.

11. Abbas Z, Swamy NGN. Mucoadhesive microspheres as intranasal drug delivery systems: a review. Indian Drugs 2012;49:5-23.

12. Gavini E, Hegge AB, Rassu G, Sanna V, Testa C, Pirisino G, et al. Nasa administration of carbamazepine using chitosan microspheres: in vitro/in vivo studies. Int J Pharm 2006;307:9-15. 